\title{
Experimental study of the relationship between porosity and surface area of carbonate reservoir rocks
}

\author{
Milad Mohammadi $^{1}$ - Seyed Reza Shadizadeh ${ }^{1} \cdot$ Abbas Khaksar Manshad $^{1} \cdot$ Amir H. Mohammadi $^{2}$
}

Received: 19 July 2019 / Accepted: 11 January 2020 / Published online: 18 February 2020

(c) The Author(s) 2020

\begin{abstract}
Over the time by increasing global demand for source of energy and decreasing hydrocarbon production from reservoirs, recovery methods have become important. The surface area and porosity are central physical characteristics that highly affect the estimation of original oil and gas in place and understanding the mechanisms incorporating in production. The surface area is the internal surface area per unit of pore volume and determines the amount of space in rocks exposed to injectant during injection operation. The occurrence of fractures system in carbonated reservoirs increases the complexity and decreases the homogeneity; hence, it is difficult to determine the correct surface area of reservoir. Therefore, the existence of a local correlation which relates effective porosity to specific surface area is needed and it can help to estimate effective surface area exposed to chemicals during Enhanced Oil Recovery (EOR) process. In this study, the specific surface area in carbonate reservoir rocks was measured by gas adsorption (nitrogen) method and petro-graphical image analysis. In addition, the effective porosity was determined by a gas porosimeter, followed by plotting specific surface area measured by the Brunauer, Emmett and Teller (BET) method versus specific surface area determined from core scan and calibration curve. According to this calibration curve, a new relationship was developed (with $R^{2}=0.92$ ) that could give BET data for a known data of core scan. The relationship between porosity and specific surface area was analyzed statistically and a relationship with accuracy of $R^{2}=0.89$ was proposed. This relationship was compared with other models such as Pirson and Kotyakhov. Results show that the latter one is more accurate than other models and is more compatible with experimental data (with $R^{2}=0.84$ ). The results obtained from the experiment indicate that the specific surface area shows an initial decrease upon increasing of porosity up to 0.2. After this decrease, the curve indicates an increasing trend. Moreover, a novel relationship was developed depending on the specific surface area, porosity and permeability and some constant parameters for carbonate rocks (with $R^{2}=0.95$ ).
\end{abstract}

Keywords Porosity $\cdot$ Surface area $\cdot$ Carbonate rocks $\cdot$ Reservoir

\section{Introduction}

Because of high rate of energy consumption and challenges and high expenses of petroleum production, researchers are continually seeking effective methods to enhance its

Abbas Khaksar Manshad

khaksar@put.ac.ir; akmanshad113@gmail.com

$\bowtie$ Amir H. Mohammadi amir_h_mohammadi@yahoo.com

1 Department of Petroleum Engineering, Abadan Faculty of Petroleum Engineering, Petroleum University of Technology (PUT), Abadan, Iran

2 Discipline of Chemical Engineering, School of Engineering, University of KwaZulu-Natal, Howard College Campus, King George V Avenue, Durban 4041, South Africa recovery (Evbuomwan 2009). Through the producing life of a reservoir, recovery is summarized in three phases: primary, secondary and tertiary. In primary recovery, the predominant mechanism is natural drive energy of the reservoir. In this phase, the injection of any external fluids or heat as a driving energy is not necessary. The main mechanisms of primary production are rock and fluid expansion, solution gas, water influx, gas cap and gravity drainage. Through secondary recovery, an external fluid, such as water and/or gas, is injected for purpose of pressure maintenance and volumetric sweep of reservoir fluid. Tertiary recovery is described by the injection of special fluids such as chemicals, miscible gases and/or the injection of thermal energy (Sheng 2010).

The chemical flooding is one of common methods of tertiary recovery. The primary goal in chemical EOR or chemical flooding is to recover more petroleum by either one or a

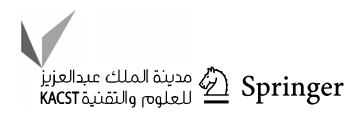


combination of the following processes: (1) mobility control by adding polymers to reduce the mobility of the injected water; (2) reducing interfacial tension (IFT) by utilizing surfactants and/or alkalis (Hosseini et al. 2018).

In the chemical injection such as surfactant flooding, it is necessary to determine the volume of chemical injectant before injection into reservoir. Therefore, it is essential to determine surface area of grains. Since this parameter is not sensible in petroleum engineering, it should be correlated with a known petro-physical parameter such as the porosity.

The aim of this study was to find a reliable relationship between porosity and surface area of carbonate rocks based on experimental results. The results in this study can be applied to chemical enhanced oil recovery process. Another usage of correlation between surface area and porosity is in reservoir characterization and simulation. Another objective of this study was finding an experimental correlation for core scan device by which specific surface area data of the BET test is gained from specific surface area data by using core scan device. In this study, in order to maximize accuracy, other petro-physical parameters could be used in the experimental correlation. In this work, in addition to $\emptyset$, $k$ is also added and maximum accuracy is accomplished.

\section{Literature review}

Basbug and Karpyn (2007) examined a relation between permeability estimations and rock properties such as porosity, specific surface area and irreducible water saturation. They observed a direct relationship between porosity and permeability, and both irreducible water saturation and specific surface area tend to lower permeability. Irreducible water saturation and surface area both decrease by increasing permeability. Irreducible water saturation increases with specific surface area for most reservoir formations. Predicted permeabilities at constant specific surface area show insignificant variations with the change in irreducible water saturation, indicating the connection between specific surface area and irreducible water saturation. They suggested the following correlation:

$k=\frac{\emptyset^{3}}{2 \tau(1-\emptyset)^{2} S_{t}^{2}}$

in which $k$ is the permeability $(\mathrm{mD})$; $\emptyset$ is the porosity; $\tau$ represents the tortuosity; and $S_{t}$ is the specific surface area $(1 / \mathrm{cm})$.

Donaldson et al. (1975) measured the surface area of glass spheres and 5 types of sandstones by gas chromatography flow method and compared the measured data with surface area determined by Carman-Kozeny correlation, and average particle diameter for consistency. They observed an excellent agreement between the surface areas from Carman-Kozeny equation and nitrogen adsorption for glass beads. The ratio between the gas adsorption and Carman-Kozeny surface area was undoubtedly. They recommended the following relation:

$A_{\mathrm{s}}=31.8 \rho_{\mathrm{b}}^{-1}\left(\frac{\emptyset^{3}}{k F_{\mathrm{t}}}\right)^{1 / 2}$

where $A_{\mathrm{s}}$ is the surface area $\left(\mathrm{m}^{2} / \mathrm{gr}\right), \rho_{\mathrm{b}}$ represents the bulk density ( $\mathrm{gr} / \mathrm{cc}), \emptyset$ presents for the porosity, $k$ is the permeability $(\mathrm{mD})$, and $F_{\mathrm{t}}$ represents the textural factor.

Brooks and Purcell (1952) measured the surface area of the variety of sandstone and limestone cores by gas adsorption method. The measured surface areas varied between $0.5-6 \mathrm{~m}^{2} /$ gr and $0.05-0.5 \mathrm{~m}^{2} / \mathrm{gr}$ for sandstone and limestone, respectively. They compared the surface areas determined from Carman-Kozeny equation and geometrical areas of spherical glass beads. For sandstone cores, Kozeny areas were compared with results of gas adsorption method. For glass beads, surface areas were nearly equal to geometrical surface area of beads, the Kozeny area agreed fairly well with BET area. The following equation was obtained:

$S=\frac{31.8 f}{\rho[1-f]} \sqrt{\frac{f}{k K}}$

where $S$ is the surface area $\left(\mathrm{m}^{2} / \mathrm{gr}\right), \rho$ represents the density of the solid $(\mathrm{gr} / \mathrm{cc}), f$ stands for the fractional porosity, $k$ is the non-dimensional textural factor, and $K$ represents the permeability $(\mathrm{mD})$.

Wyllie and Rose (1950) modified the Carman-Kozeny equation and substituted irreducible water saturation by specific surface area. They conjectured that the surface area of grain is approximately related to irreducible water saturation and expressed an equation as:

$k^{1 / 2}=B \frac{\varphi^{3}}{S_{\text {wir }}-B^{\prime}}$

where $B$ and $B^{\prime}$ are constants, and a generalized Wyllie-Rose relationship is sometimes written as:

$k=\frac{P \varphi^{Q}}{S_{\mathrm{wir}}^{R}}$

where $P, Q$ and $R$ are tuning parameters to be calibrated from the fit to core measurements.

Li and Engler (2001) in another attempt obtained:

$k=\frac{\varphi^{-y}}{2.24 F^{y+1} S_{\mathrm{pv}}^{2}}$

where $S_{\mathrm{pv}}$ is the internal surface area of the pores per unit pore volume, $F$ is the formation resistivity factor, and $Y$ represents a tuning parameter. 


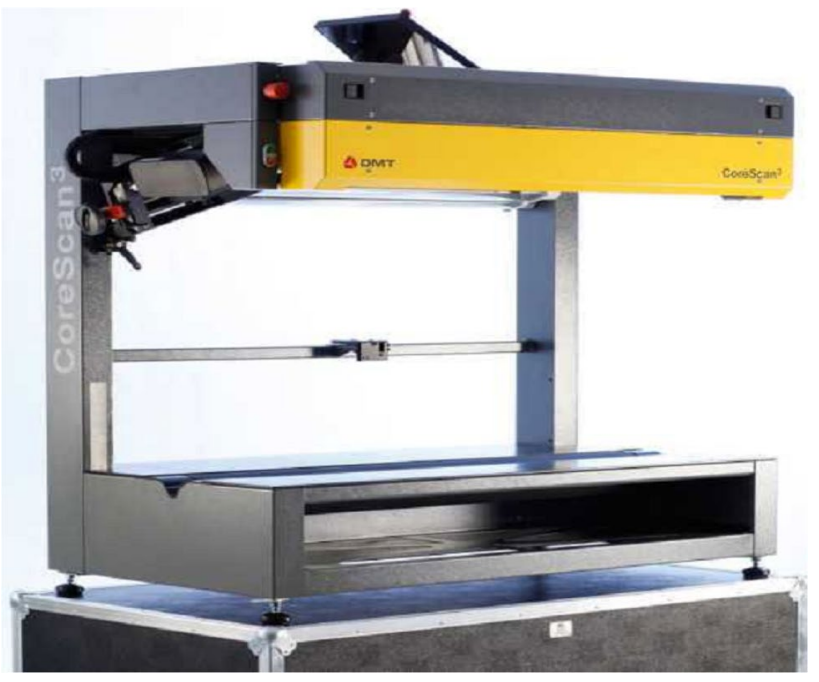

Fig. 1 DMT $^{3}$ core scan

Chilingarian et al. (1990) studied the interrelationship among permeability, porosity, specific surface area and residual water saturation by using multivariable linear regression for four carbonate reservoir rocks of Russia. The coefficient of correlation $R^{2}$ varied in the range of 0.981-0.997. The following relation was obtained:

$$
\begin{aligned}
\log k= & 0.9532-2.788 \times 10^{-2} S_{\mathrm{wr}}-5.5597 \times 10^{-4} S_{\mathrm{s}} \\
& +1.3309 \times 10^{-1} \emptyset+1.1707 \times 10^{-5} S_{\mathrm{wr}} S_{\mathrm{s}}
\end{aligned}
$$

where $K$ is the permeability (mD), $S_{\text {wr }}$ represents the residual water saturation (\%), $S_{\mathrm{s}}$ represents for the specific surface area $(1 / \mathrm{cm})$, and $\emptyset$ is the porosity.
Fatt and Kumar (1970) studied the porosity, permeability and surface area of unconsolidated porous media under dynamic conditions by using NMR spectrometry. They found a linear relationship between relaxation time and specific surface grains and an exponential relationship between permeability and relaxation time. No definite relation was observed between porosity and relaxation time. They used spherical particles assumption in calculation of surface area. They proposed the following linear relation:

$S=3.5 \times 10^{3}\left(0.507-T_{1}\right)$

where $S$ is the specific surface area $(1 / \mathrm{cm})$ and $T_{1}$ represents the longitudinal relaxation time (s).

Mortensen et al. (2013) investigated the relationship between permeability and porosity for Danian and Maastrichtian chalk from Gorm field offshore Denmark based on 300 sets of core data. The specific surface area was measured by BET and image analysis. They validated Carman-Kozeny equation and also found that the nature of porosity had no significant influence on the air permeability. They realized that determination of specific surface area by image analysis fails for particles with large ratios between surface area and grain volume. It was also observed that each lithologic unit has a characteristic specific surface. They found that specific surface, rather than grain size, determines the permeability.

$K=C \frac{\emptyset^{3}}{(1-\emptyset)^{2} S_{\mathrm{s}}^{2}}$

where $K$ is the permeability $(\mathrm{mD}), C$ stands for Carman-Kozeny's factor, $\emptyset$ represents the porosity, and $S_{\mathrm{s}}$ is the specific surface area $(1 / \mathrm{cm})$.

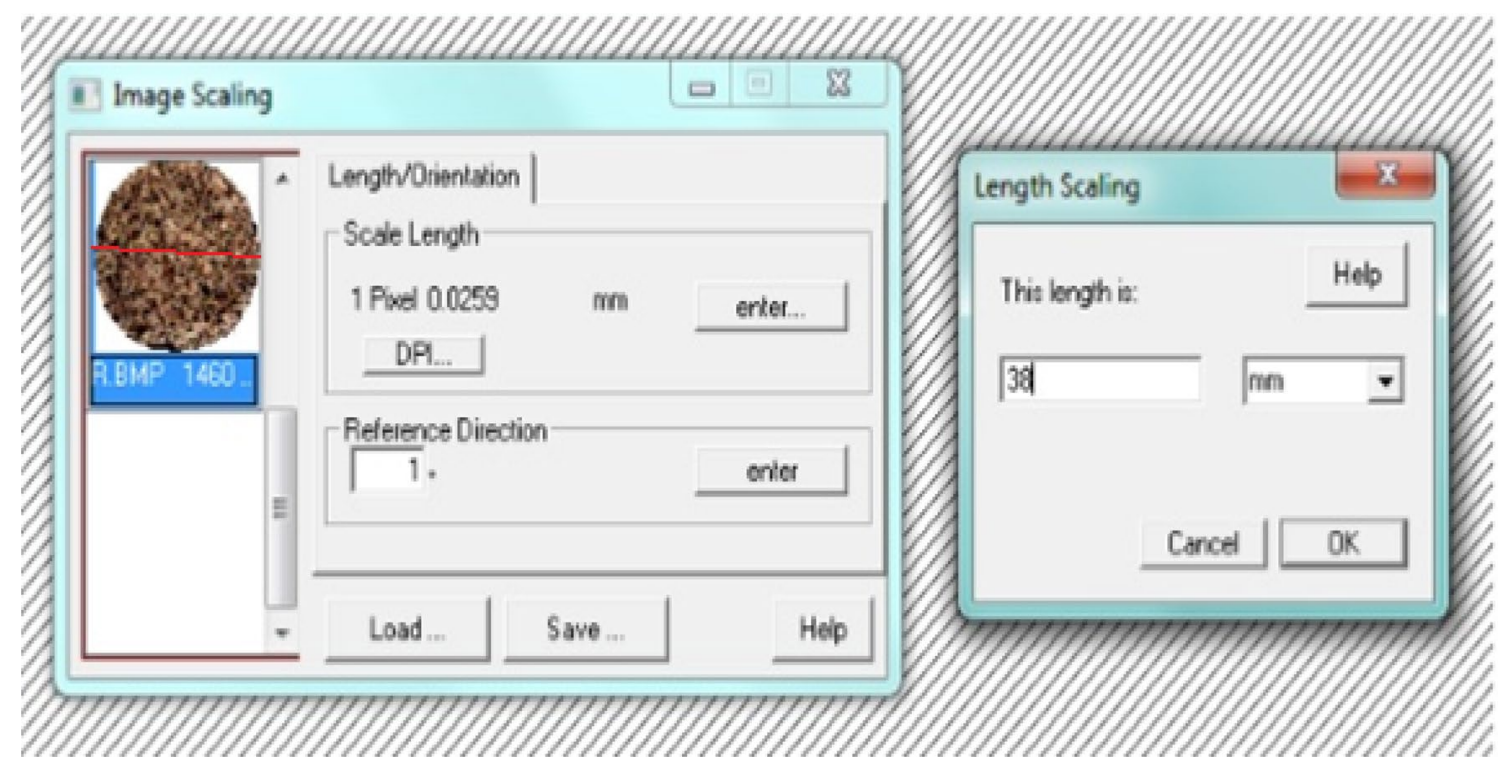

Fig. 2 Image scaling definition (Zafari 2014)

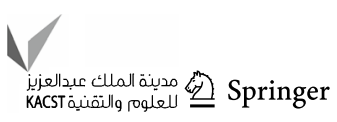




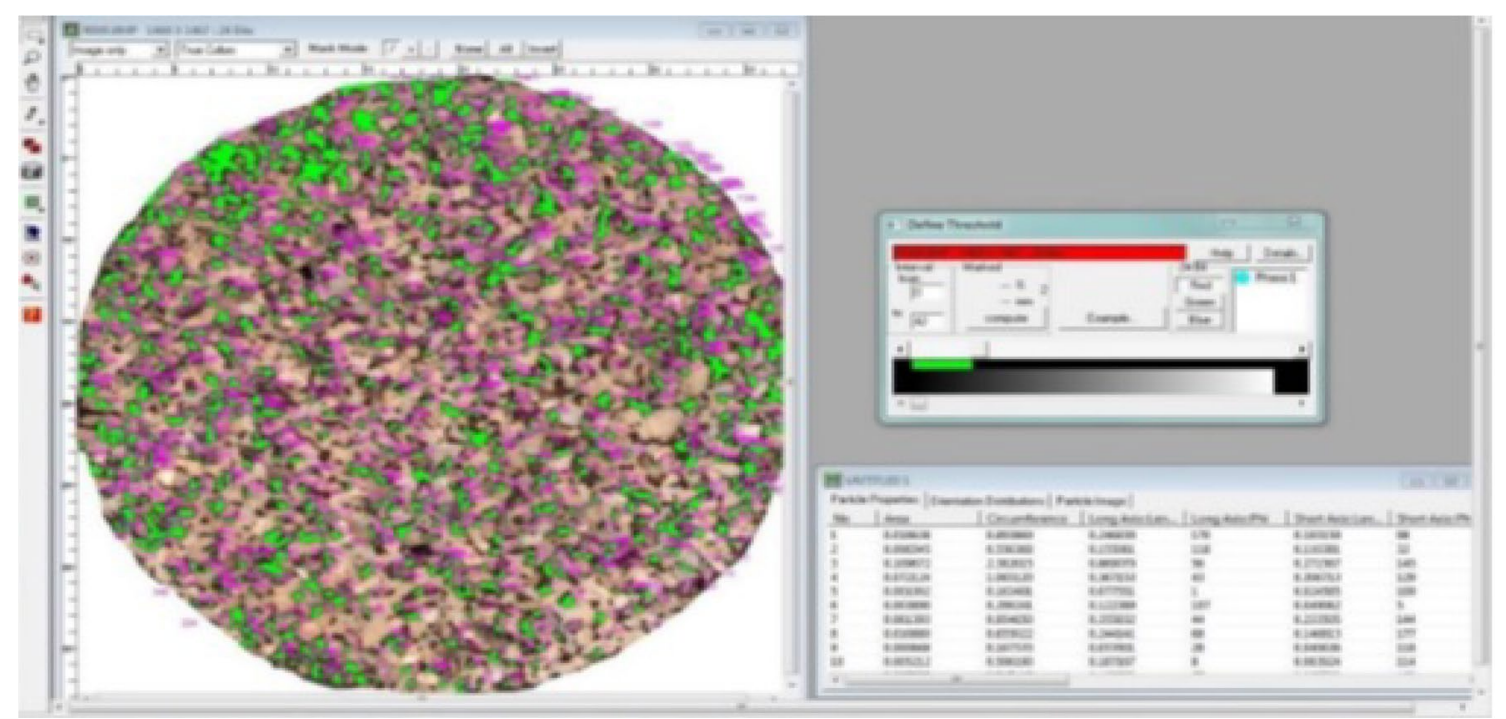

Fig. 3 Threshold definition (Zafari 2014)

Fig. 4 Particle size distributions of carbonate chips (K1, K3, A1 and $\mathrm{K} 4$ ) determined from 2-D scanning (purple: surface area value; green: matrix)

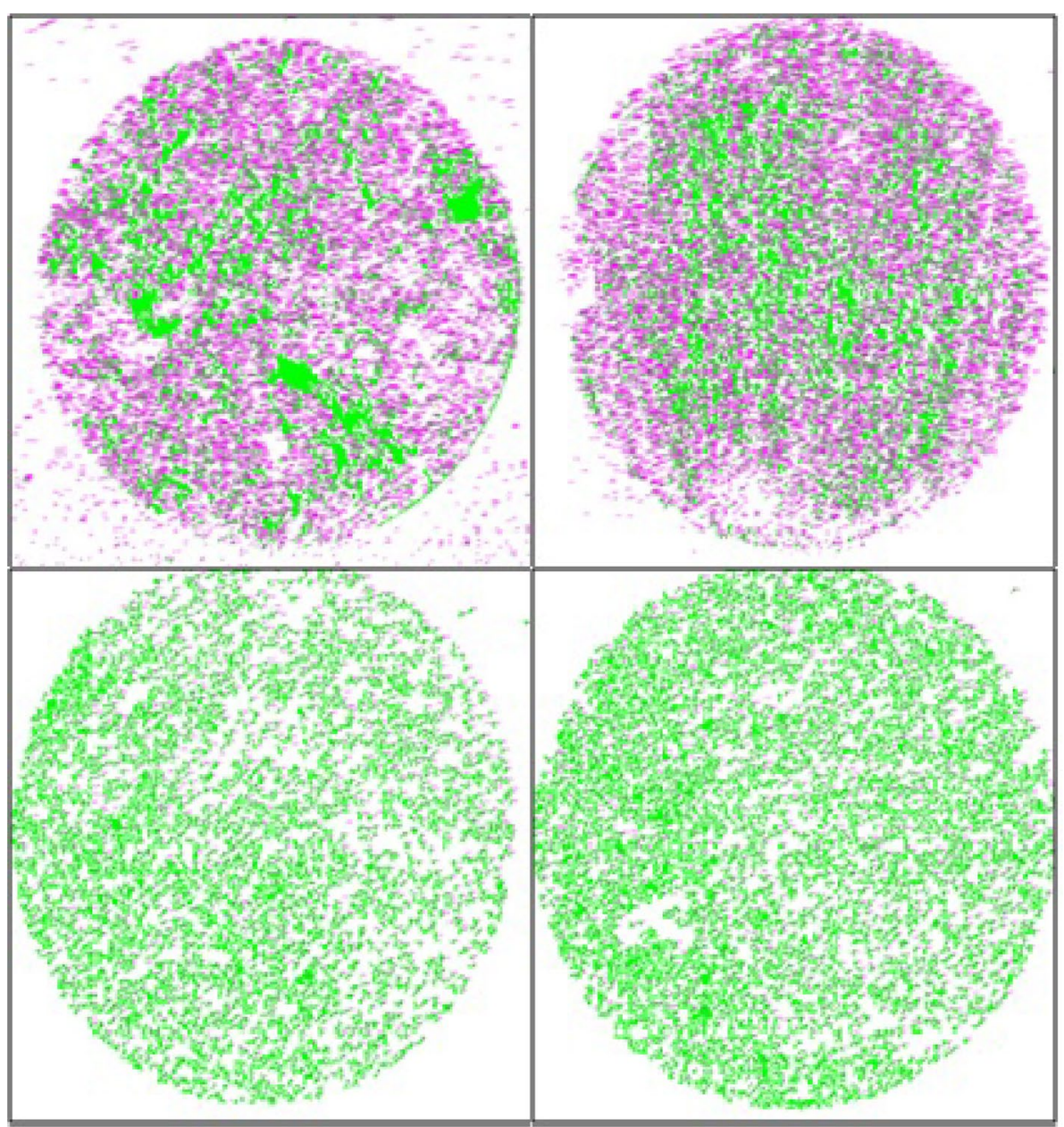


Lee and Lee (2013) investigated effects of specific surface area and porosity on cube counting fractal dimension, lacunarity, configuration entropy and permeability of porous networks. They established relationships among porosity, specific surface area, structural parameters and the corresponding macroscopic properties. They found cubic counting dimension of 3D networks increases with increasing specific surface area at a constant porosity and with increasing porosity at a constant specific surface area. They also concluded that the maximum configurationally entropy increases with increasing porosity and the entropy length of the pores decreases with increasing specific surface area, which were used to calculate the average connectivity among the pores. The following equation was obtained:

$K(\emptyset, S)=\frac{\emptyset^{3}}{C_{0} S^{2}(1-\emptyset)^{2}}$

where $K$ is the permeability ( $\mathrm{mD}), \emptyset$ represents the porosity, $C_{0}$ stands for the pore shape factor, and $S$ is the specific surface area $\left(\mathrm{mm}^{2}\right)$.

It can be concluded from the literature review that careful examination of geological and petro-physical properties such as surface area is necessary which confined close relation to rock type, and controlling reservoir performance. It is in order to investigate the relationship between porosity and surface area of carbonate rocks. Hence, it is better to apply the petrographic image analysis (PIA) because it provides quantitative evaluations from standard core plugs. Moreover, PIA has become a fast, low cost and routine evaluation tool. Digital image analysis and gas adsorption method are applied to determination surface area of core plug samples.

\section{Equipment and experimental procedure}

\section{Equipment}

\section{Core scan}

Core scan is a portable core imaging device developed for core image acquisition, storage and evaluation of full and slabbed core. Furthermore, whole core boxes can be compiled to one image. Full core is rotated $360^{\circ}$ around its cylindrical axis, while the line-scan camera is positioned parallel to the axis of rotation and scans core surface. The core is scanned by rate of about $20 \mathrm{~s} / \mathrm{m}$, and the image is captured (Tiab and Donaldson 2011).

The configuration of DMT core scan equipment is as follows (Fig. 1):

- Dimensions: length: $1.36 \mathrm{~m}$, depth: $0.75 \mathrm{~m}$, height: $1.28 \mathrm{~m}$, weight: $128 \mathrm{~kg}$.

- Electric power supply: voltage 110-250 VAC, $50 \mathrm{~Hz} / 60 \mathrm{~Hz}$; power $\left(p_{\max }\right) 500 \mathrm{VA}$.

- Core length: up to $1 \mathrm{~m}$ (full circumference and slabbed cores).

- Core diameter: $25-150 \mathrm{~mm}$ (unrolled core), up to $250 \mathrm{~mm}$ (slabbed).

\section{(a)}

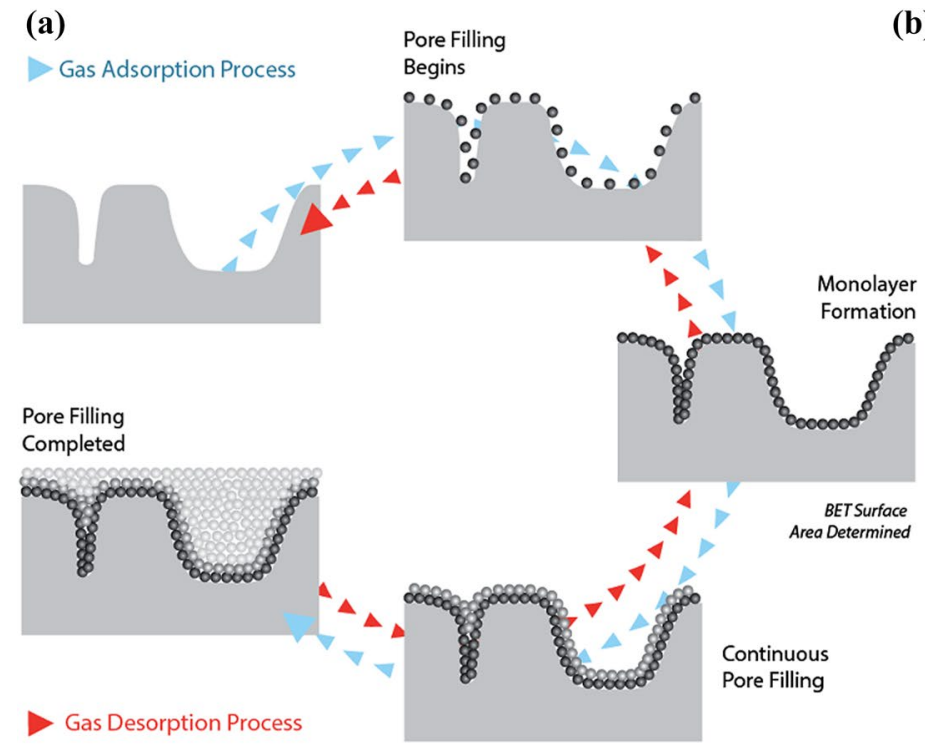

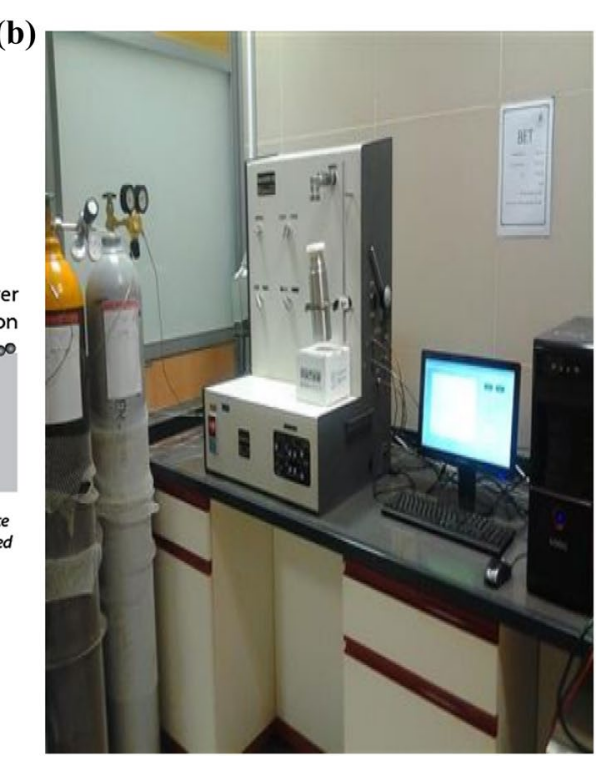

Fig. 5 a Adsorption and desorption process in BET test. b BET test instrument 
- Resolution: 5, 10 and 40 pixel/mm (127 250 and 1000 dpi) (Zafari 2014).

\section{Porosimeter}

This apparatus is used to measure porosity using Boyl's law. It contains two chambers (sample and reference chamber), a pressure regulator, and two pressure gauges, expansion valve, and gas source.

\section{Gas permeameter}

Gas permeameter is used to measure permeability based on Darcy's law. It contains a core holder, two valves (upstream and downstream valve), a pressure regulator, confining valve and gas source $\left(\mathrm{N}_{2}\right)$. It was used to quantify the permeability.

\section{Experimental procedure}

\section{Plug preparation}

First, eight carbonate plug samples were taken from cores vertically by using plugging machine. Then, they were cleaned in Soxhlet for 1 day and dried in oven at $70{ }^{\circ} \mathrm{C}$ for $12 \mathrm{~h}$.

\section{Porosity measurement of plugs}

After drying the plugs, their dimensions (diameter, length) and weight were measured by caliper and digital balance, respectively. The plugs were placed in sample chamber, and then the chamber was closed. The device turned on, and input data were entered.

After recording the data, porosity is measured by using Boyle's law:

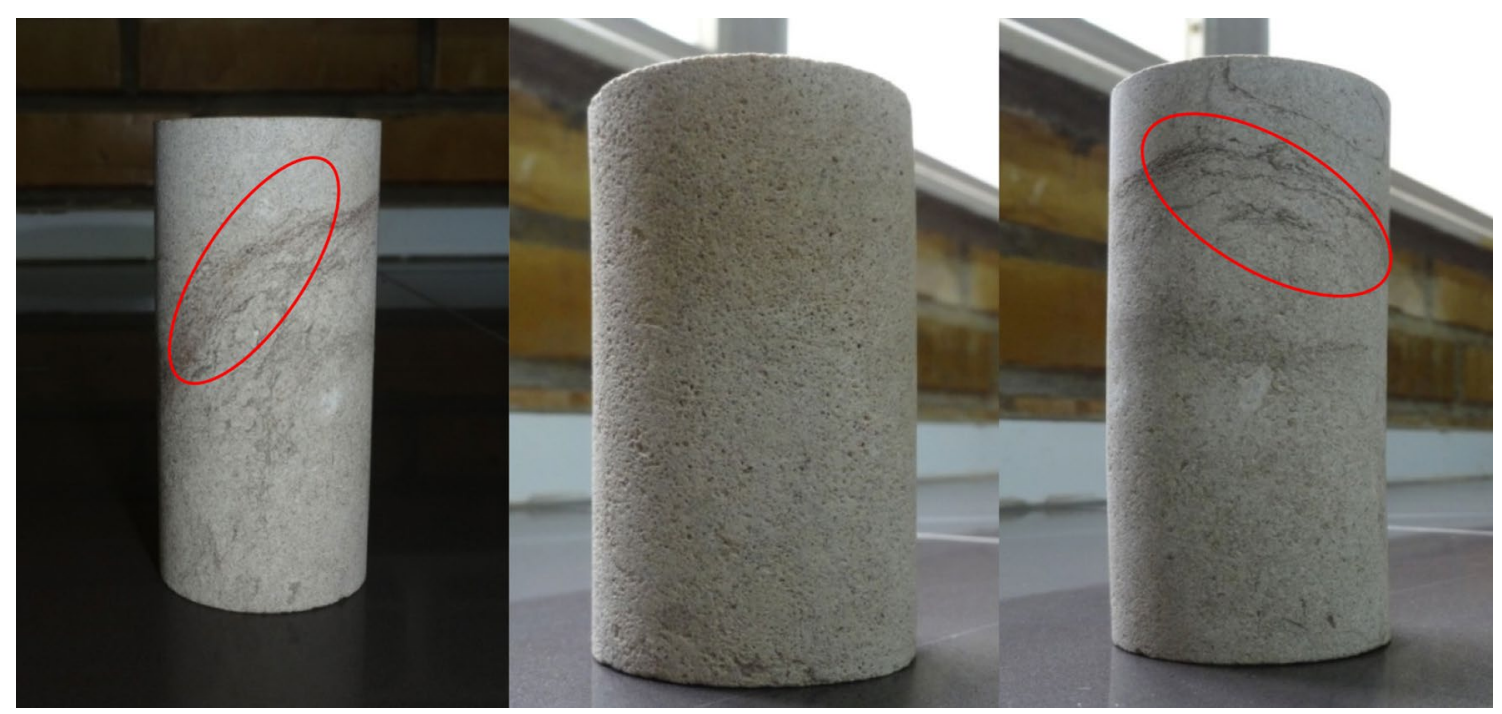

Fig. 6 Carbonate core samples

Table 1 Properties of core samples

\begin{tabular}{lllllllll}
\hline Sample & Depth $(\mathrm{m})$ & Rock type & $L(\mathrm{~mm})$ & $D(\mathrm{~mm})$ & $K(\mathrm{mD})$ & $\emptyset(\%)$ & $W(\mathrm{gr})$ & $\begin{array}{l}\text { Average specific sur- } \\
\text { face area of plugs }\left(\mathrm{m}^{2}\right)\end{array}$ \\
\hline K1 & $2500-3000$ & Carbonate & 78.46 & 37.05 & 0.6 & 8.11 & 206.69 & 373.505 \\
K3 & $2500-3000$ & Carbonate & 71.11 & 36.92 & 1.5 & 14.51 & 179.77 & 293.656 \\
K4-D1 & 2300 & Carbonate & 25.37 & 37.01 & 3.1 & 12.25 & 58.97 & 391.491 \\
A1 & $2500-3000$ & Carbonate & 67.33 & 37.43 & 0.8 & 14.5 & 176.15 & 241.454 \\
B1 & $2500-3000$ & Carbonate & 64.21 & 37.39 & 0.33 & 32 & 174.68 & 132.159 \\
B2 & $2500-3000$ & Carbonate & 61.48 & 37.45 & 1.75 & 35 & 171.25 & 147.804 \\
B3 & $2500-3000$ & Carbonate & 73.65 & 37.36 & 2.34 & 31 & 181.37 & 218.328 \\
B4 & $2500-3000$ & Carbonate & 40.14 & 37.38 & 1.43 & 28 & 89.98 & 147.743 \\
\hline
\end{tabular}


Table 2 Porosimeter data

\begin{tabular}{llllllll}
\hline Sample & $P_{1}(\mathrm{psi})$ & $P_{2}(\mathrm{psi})$ & $T\left({ }^{\circ} \mathrm{C}\right)$ & $V_{\mathrm{b}}(\mathrm{cc})$ & $V_{\mathrm{p}}(\mathrm{cc})$ & $\rho_{\mathrm{gr}}(\mathrm{gr} / \mathrm{cc})$ & $\emptyset(\%)$ \\
\hline A1 & 139.36 & 46.61 & 23.6 & 74.05 & 11.63 & 2.78 & 14.5 \\
K1 & 139.36 & 56.71 & 23.2 & 84.55 & 7.7 & 2.66 & 8.11 \\
K3 & 139.36 & 31.32 & 22.9 & 76.1 & 9.8 & 2.76 & 14.51 \\
K4-D1 & 139.36 & 48.69 & 22.9 & 27.28 & 2.75 & 2.46 & 12.25 \\
B1 & 139.36 & 43.28 & 23.2 & 72.14 & 23.08 & 2.68 & 32 \\
B2 & 139.36 & 43.91 & 23.2 & 70.83 & 24.79 & 2.66 & 35 \\
B3 & 139.36 & 46.29 & 23.2 & 80.67 & 25 & 2.64 & 31 \\
B4 & 139.36 & 45.74 & 23.2 & 51.38 & 14.38 & 2.52 & 28 \\
\hline
\end{tabular}

Fig. 7 The carbonate chip samples (B1 and B2 samples)
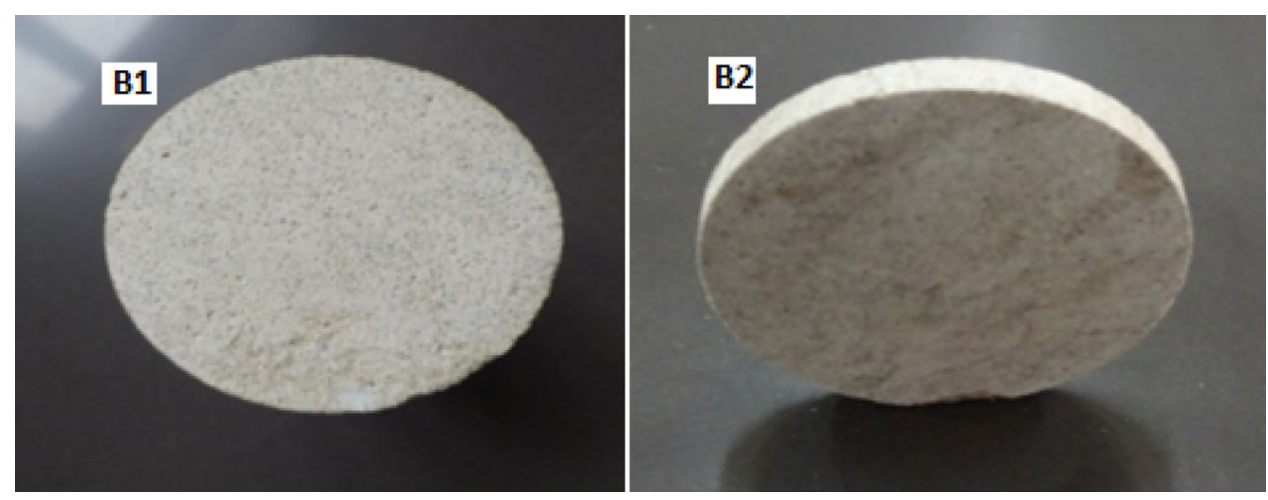

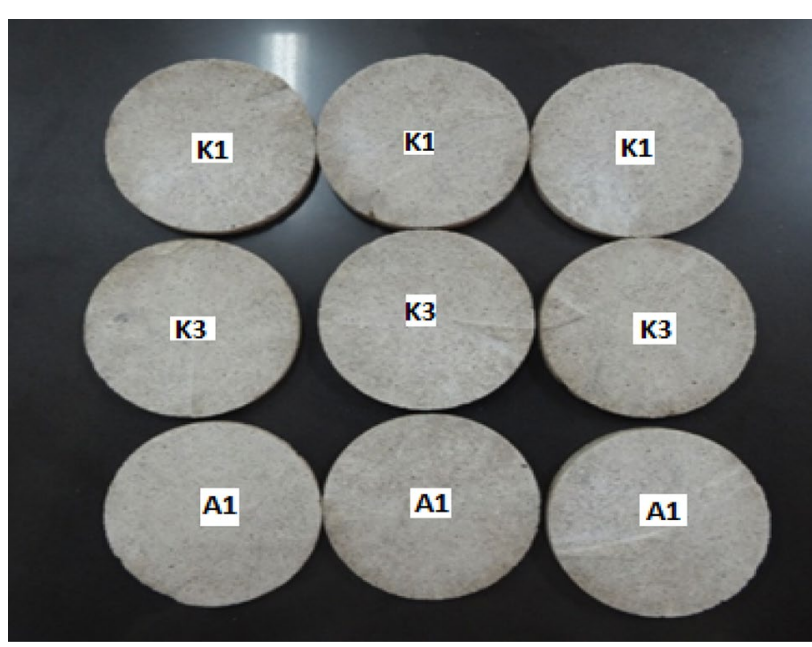

Fig. 8 Selected carbonate chips (K1, K3 and A1 samples) for BET test

$$
\begin{aligned}
& P_{1} V_{\text {ref }}=P_{2}\left(V_{\text {ref }}+V_{\text {sam }}-V_{\mathrm{g}}\right) \\
& V_{\mathrm{g}}=\frac{P_{2} V_{\text {ref }}+P_{2} V_{\text {sam }}-P_{1} V_{\text {ref }}}{P_{2}}
\end{aligned}
$$

where $V_{\text {ref }}$ and $V_{\text {sam }}$ are volumes of reference and sample chamber cells, respectively (cc). $V_{\mathrm{g}}$ is the grain volume of plug sample (cc). $P_{1}$ is the inlet pressure and $P_{2}$ is the equilibrium pressure after opening outlet valve (psi).

\section{Permeability measurement}

The core plug was placed in core holder. After the confining valve is opened, $\mathrm{N}_{2}$ enters the plug sample. The mean pressure is regulated by a pressure regulator on the sides of core holder. The rate is measured at atmospheric conditions with a mass flow. $\mathrm{N}_{2}$ viscosity is available as a function of temperature is in reference books. Four measuring air permeability were taken at different pressures. It is important to have relative little pressure difference, $\Delta P$. Finally, the Klinkenberg effect was corrected by the following equation:

$k_{1}=\frac{K_{\mathrm{g}} P_{\mathrm{m}}}{P_{\mathrm{m}}+b}$

$k_{\mathrm{g}}$ is the gas permeability (mD), $k_{1}$ is the liquid permeability $(\mathrm{mD}), b$ is a constant, and $p_{\mathrm{m}}$ is the mean pressure (psi). 
Table 3 Upper and lower thresholds, specific surface area of top and bottom surfaces and average of specific surface area and average of specific surface of plug sample in K3 sample

\begin{tabular}{lllll}
\hline Chip no. & High threshold & Low threshold & $\begin{array}{l}\text { Specific surface } \\
\text { area }\left(\mathrm{m}^{2}\right)\end{array}$ & $\begin{array}{l}\text { Average of specific surface } \\
\text { area of each chip }\left(\overline{S_{\text {sc }}}\right)\left(\mathrm{m}^{2}\right)\end{array}$ \\
\hline 1 Top & 237 & 126 & 254.408 & 303.424 \\
1 Bottom & 237 & 126 & 352.440 & \\
2 Top & 238 & 131 & 255.412 & 275.932 \\
2 Bottom & 238 & 131 & 296.452 & \\
3 Top & 221 & 118 & 437.444 & 359.658 \\
3 Bottom & 225 & 138 & 281.872 & \\
4 Top & 225 & 138 & 357.124 & 327.679 \\
4 Bottom & 228 & 135 & 298.235 & \\
5 Top & 228 & 135 & 383.452 & 348.868 \\
5 Bottom & 228 & 135 & 314.285 & \\
6 Top & 228 & 135 & 297.725 & 286.923 \\
6 Bottom & 230 & 135 & 276.122 & \\
7 Top & 233 & 120 & 218.742 & 237.860 \\
7 Bottom & 233 & 120 & 256.979 & \\
8 Top & 233 & 120 & 313.025 & 348.989 \\
8 Bottom & 233 & 120 & 384.953 & \\
9 Top & 266 & 139 & 248.123 & 234.902 \\
9 Bottom & 266 & 139 & 221.681 & \\
10 Top & 266 & 139 & 226.864 & 242.328 \\
10 Bottom & 266 & 139 & 257.792 & \\
\hline Avage & & & & \\
\end{tabular}

Average specific surface area of plug sample $\left(\overline{S_{\mathrm{sp}}}\right)$ is 289.491
A selectable, separate back pressure flow facility permits accurate control of steady state gas flow and core pressure over the range of $0-2000 \mathrm{cc} / \mathrm{min}$ and $0-150 \mathrm{psi}$, enabling a greater control on Darcy flow conditions in cores with permeabilities in the range from less than $0.1 \mathrm{mD}$ to in excess of $10 \mathrm{D}$. Typically, four different ranges of mass flow meters including $0-20,0-50,0-500$ and $0-2000 \mathrm{cc} / \mathrm{min}$ assist the operators to measure different ranges of permeability $(0.01-10,000 \mathrm{mD})$. The instrument can be used with any standard Hassler-type core holder. Rapid change over of core holder is permitted to switch from core diameter of 1" and 1"1/2 or any other diameter on request. Confining pressures up to 200 psig can be applied to the cores and displayed on the GasPerm console.

\section{Cutting the plugs}

In this stage, a plug was cut into 2-4-mm-thick chips and their surfaces were polished. Each plug was divided into about 10 chips. After that, porosity and permeability of the chips were measured.

\section{Scanning the chips sample}

The chip was placed inside the $\mathrm{DMT}^{3}$ core scanner under high-resolution camera. When the camera was reached to an acceptable focus manually on surface of the chips, the scanning process was started. Top and bottom surfaces of chips were scanned in plane mode. In plane or fixed mode, the sample is placed under camera directly and is fixed. Camera sees sample in mirror and starts to scan (Torsaeter and Abtahi 2003).

\section{Determining of specific surface area of chips by core scan $\mathrm{DMT}^{3}$}

Core scan instrument requires conditions before scanning the samples. These conditions include definition of scale and threshold for each scan. In this study, it was devised that scan conditions be constant for each plug.

Image processing Image processing includes several steps to reach the most quality for digital images, which includes scaling, threshold definition and particle size indicators. Finally, the specific surface area of samples could be obtained (Zafari 2014).

Scaling definition The initial step in petro-graphical image analysis is scaling. The image must be scaled manually. When being loaded, scanned, transferred via clipboard or newly created, every image is automatically provided with basic scaling. Some devices such as scanner and core scanner inform Core Image Analysis (CIA) about the image 
Table 4 Porosity of selected chips

\begin{tabular}{|c|c|c|c|}
\hline Sample & No. of chips & Selected chips & $\begin{array}{l}\text { Porosity of } \\
\text { selected chips } \\
(\%)\end{array}$ \\
\hline \multirow[t]{4}{*}{ K1 } & 12 & 2 & 8.16 \\
\hline & & 4 & 7.7 \\
\hline & & 7 & 7.2 \\
\hline & & 11 & 8.76 \\
\hline \multirow[t]{3}{*}{ K3 } & 10 & 1 & 12.98 \\
\hline & & 6 & 13.21 \\
\hline & & 8 & 16.34 \\
\hline \multirow[t]{2}{*}{ K4 } & 6 & 2 & 12.06 \\
\hline & & 5 & 12.33 \\
\hline \multirow[t]{3}{*}{ A1 } & 9 & 4 & 14.44 \\
\hline & & 6 & 13.83 \\
\hline & & 7 & 14.09 \\
\hline \multirow[t]{4}{*}{ B1 } & 12 & 1 & 25 \\
\hline & & 4 & 23.3 \\
\hline & & 9 & 28.5 \\
\hline & & 11 & 28.5 \\
\hline \multirow[t]{3}{*}{ B2 } & 10 & 2 & 29.2 \\
\hline & & 6 & 36.3 \\
\hline & & 10 & 30.9 \\
\hline \multirow[t]{5}{*}{ B3 } & 15 & 3 & 43.2 \\
\hline & & 5 & 32.9 \\
\hline & & 8 & 28.6 \\
\hline & & 11 & 33.8 \\
\hline & & 13 & 30.8 \\
\hline \multirow[t]{2}{*}{ B4 } & 8 & 4 & 36 \\
\hline & & 6 & 35.3 \\
\hline
\end{tabular}

scale. These images will assign the last scaling that the user has entered. As shown in Fig. 2, the special known segment in the image was selected and real length of segment was given to the software (Zafari 2014).

Threshold definition Core Image Analysis recognizes particle or features in the image by their shape, color or by their gray value (lightness). Before particles are indicated, a threshold must be selected which defines the range of colors or gray values that contain the particles or features to be measured (Fig. 3) (Zafari 2014).

Automatic particle indication First, the dimension intended to measure was selected. We have to choose type of measurement automatically or manually. Automatic measurement is possible if the objects can be separated from the background and from each other by their gray or color values or by filtering the image. When measuring automatically, CIA searches for particles in the image and evaluates them without any user intervention. CIA calculates the shape parameter defined in the measurement list for each particle.
Table 5 Permeability of selected chips

\begin{tabular}{|c|c|c|c|}
\hline Sample & No. of chips & Selected chips & $\begin{array}{l}\text { Permeability of } \\
\text { selected chips } \\
(\mathrm{mD})\end{array}$ \\
\hline \multirow[t]{4}{*}{ K1 } & 12 & 2 & 0.8 \\
\hline & & 4 & 0.39 \\
\hline & & 7 & 0.61 \\
\hline & & 11 & 0.23 \\
\hline \multirow[t]{3}{*}{ K3 } & 10 & 1 & 1.26 \\
\hline & & 6 & 1.71 \\
\hline & & 8 & 1.45 \\
\hline \multirow[t]{2}{*}{ K4 } & 6 & 2 & 2.98 \\
\hline & & 5 & 3.15 \\
\hline \multirow[t]{3}{*}{ A1 } & 9 & 4 & 0.93 \\
\hline & & 6 & 0.71 \\
\hline & & 7 & 0.76 \\
\hline \multirow[t]{4}{*}{ B1 } & 12 & 1 & 1.65 \\
\hline & & 4 & 0.52 \\
\hline & & 9 & 1.04 \\
\hline & & 11 & 1.04 \\
\hline \multirow[t]{3}{*}{ B2 } & 10 & 2 & 1.83 \\
\hline & & 6 & 3.29 \\
\hline & & 10 & 0.58 \\
\hline \multirow[t]{5}{*}{ B3 } & 15 & 3 & 4.61 \\
\hline & & 5 & 0.98 \\
\hline & & 8 & 0.28 \\
\hline & & 11 & 0.58 \\
\hline & & 13 & 0.3 \\
\hline \multirow[t]{2}{*}{ B4 } & 8 & 4 & 0.98 \\
\hline & & 6 & 0.19 \\
\hline
\end{tabular}

Maximum and minimum size of pore can be selected to ignore pores which are out of this interval, shape parameters of pores which are less than 10 pixels cause error in evaluations. Figure 4 shows 2D particle size distribution resulted from petro-physical image analysis by core scan device.

Since core scan device is not calibrated and the scanning condition has been chosen randomly, an alternative accurate method is used which is called BET. Since the number of samples and the cost of testing are too high, several chips representing the properties of the plugs were selected for the BET test.

\section{Selection of chips for BET test}

Primarily, each plug was divided into ten chips. Upper and lower surface of each chip was scanned, and specific surface area was measured. Then, arithmetic average of surface areas for each plug was calculated, which is denoted by $\left(\overline{S_{\mathrm{sc}}}\right)$. After that, another arithmetic average is defined from the initial ten $\left(\overline{S_{\mathrm{sc}}}\right)$, called $\left(\overline{S_{\mathrm{sp}}}\right)$. Finally, for each plug the 
Table 6 Average specific surface area of selected chips by core scan for all plugs

\begin{tabular}{|c|c|c|c|}
\hline Sample & No. of chips & Selected chips & $\begin{array}{l}\text { Average of specific surface area of } \\
\text { selected chips }\left(\overline{S_{\mathrm{sc}}}\right) \text { measured by core } \\
\operatorname{scan}\left(\mathrm{m}^{2}\right)\end{array}$ \\
\hline \multirow[t]{4}{*}{ K1 } & 12 & 2 & 367.877 \\
\hline & & 4 & 374.126 \\
\hline & & 7 & 369.288 \\
\hline & & 11 & 375.983 \\
\hline \multirow[t]{3}{*}{ K3 } & 10 & 1 & 303.424 \\
\hline & & 6 & 286.923 \\
\hline & & 8 & 298.989 \\
\hline \multirow[t]{2}{*}{ K4 } & 6 & 2 & 402.738 \\
\hline & & 5 & 382.543 \\
\hline \multirow[t]{3}{*}{ A1 } & 9 & 4 & 241.876 \\
\hline & & 6 & 235.968 \\
\hline & & 7 & 244.962 \\
\hline \multirow[t]{4}{*}{ B1 } & 12 & 1 & 123.900 \\
\hline & & 4 & 129.457 \\
\hline & & 9 & 136.171 \\
\hline & & 11 & 136.171 \\
\hline \multirow[t]{3}{*}{ B2 } & 10 & 2 & 146.431 \\
\hline & & 6 & 141.221 \\
\hline & & 10 & 157.598 \\
\hline \multirow[t]{5}{*}{ B3 } & 15 & 3 & 189.697 \\
\hline & & 5 & 211.646 \\
\hline & & 8 & 223.481 \\
\hline & & 11 & 221.624 \\
\hline & & 13 & 233.901 \\
\hline \multirow[t]{2}{*}{ B4 } & 8 & 4 & 149.289 \\
\hline & & 6 & 145.603 \\
\hline
\end{tabular}

chips which have close $\left(\overline{S_{\mathrm{sc}}}\right)$ and $\left(\overline{S_{\mathrm{sp}}}\right)$ are selected. Based on the length of the plug, 2-4 chips are chosen for the BET test.

\section{Preparation of samples for BET test}

Selected chips were powdered and sieved by 80 mesh. The solid samples were pretreated by applying some combination of heat, vacuum and/or flowing gas to remove adsorbed contaminants (typically water and carbon dioxide) from atmosphere. The samples were then cooled, under vacuum, normally to cryogenic temperature $\left(77 \mathrm{~K},-195^{\circ} \mathrm{C}\right)$.

\section{BET test}

The device has to be switched on/warmed up at least $30 \mathrm{~min}$ before starting an experiment. For an analysis, the nanomaterial is filled in an instrument-specific glass holder and weighted at least three times on a microbalance. Afterward, the sample is placed in the instrument being evacuated, heated up for specific time and temperature. Afterward, the sample is cooled down and weighted again to determine possible mass losses. Now, the sample/holder is placed in the BET measurement unit and the BET analysis starts by cooling down the sample to $77 \mathrm{~K}$, followed by nitrogen injection under various pressures to determine the $\mathrm{N}_{2}$ displacement for specific surface area calculation.

The specific surface area of a powder is determined from the amount of adsorbate gas corresponding to a monomolecular layer on the surface. Physical adsorption results from relatively weak forces (van der Waals forces) between the adsorbate gas molecules and the adsorbent surface area of the test powder. The test is normally carried out at the temperature of liquid nitrogen $(77 \mathrm{~K},-195 \mathrm{~K})$. The amount of the adsorbed gas is measured by a volumetric or continuous flow method (Sheng 2010).

Desorption is reverse of adsorption; during this process, the molecules desorbed from surface that was previously saturated with adsorbate and subsequently equilibrated with 
Table 7 Specific surface area of selected chips by core scan and BET

\begin{tabular}{|c|c|c|c|}
\hline \multirow[t]{2}{*}{ Plug Sample } & \multirow[t]{2}{*}{ Selected chips } & \multicolumn{2}{|c|}{$\begin{array}{l}\text { Specific surface area (1/ } \\
\mathrm{cm})\end{array}$} \\
\hline & & Core scan & BET \\
\hline \multirow[t]{4}{*}{ K1 } & 2 & $56,262.92$ & $32,212.6$ \\
\hline & 4 & $56,632.79$ & $46,789.4$ \\
\hline & 7 & $55,240.57$ & 47,348 \\
\hline & 11 & $57,876.85$ & $40,618.2$ \\
\hline \multirow[t]{3}{*}{ K3 } & 1 & $44,150.45$ & $53,248.68$ \\
\hline & 6 & $41,813.92$ & 51,336 \\
\hline & 8 & $43,898.6$ & 61,272 \\
\hline \multirow[t]{2}{*}{ K4 } & 2 & $16,787.74$ & $29,790.6$ \\
\hline & 5 & $36,576.99$ & $39,433.8$ \\
\hline \multirow[t]{3}{*}{ A1 } & 4 & $19,851.26$ & 10,842 \\
\hline & 6 & $15,221.5$ & $11,342.4$ \\
\hline & 7 & $16,354.19$ & 12,093 \\
\hline \multirow[t]{4}{*}{ B1 } & 1 & $22,813.46$ & $24,698.20$ \\
\hline & 4 & $23,212.97$ & $26,195.76$ \\
\hline & 9 & $26,270.11$ & $26,171.83$ \\
\hline & 11 & $26,235.51$ & $27,403.04$ \\
\hline \multirow[t]{3}{*}{ B2 } & 2 & $28,143.58$ & $24,997.98$ \\
\hline & 6 & $31,201.09$ & $32,476.22$ \\
\hline & 10 & $32,105.18$ & $54,728.38$ \\
\hline \multirow[t]{5}{*}{ B3 } & 3 & $41,307.79$ & $37,009.84$ \\
\hline & 5 & $39,011.46$ & $41,351.10$ \\
\hline & 8 & $38,740.11$ & $50,780.01$ \\
\hline & 11 & $41,483.12$ & $65,537.29$ \\
\hline & 13 & $41,837.69$ & $86,373.33$ \\
\hline \multirow[t]{2}{*}{ B4 } & 4 & $45,317.17$ & $65,908.76$ \\
\hline & 6 & $43,721.64$ & $80,759.19$ \\
\hline
\end{tabular}

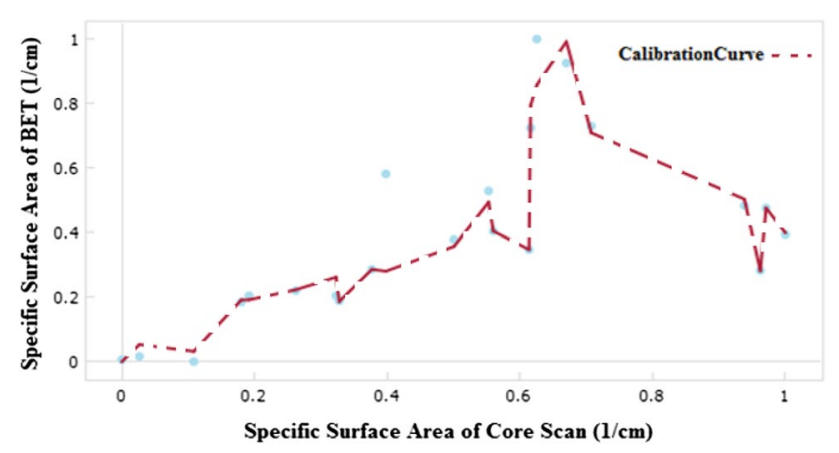

Fig. 9 Calibration curve of core scan

adsorbate of the desired relative pressure (Buryakovsky et al. 2012). Both of adsorption and desorption processes in molecular scale and also the BET test instrument are presented in Fig. 5. According to Fig. 5, stage 1 isolated sites on the sample surface begin adsorbing gas molecules at low pressure, stage 2 illustrates the gas pressure increases and coverage of adsorbed molecules - to form a monolayer (one molecule thick), and in stage 3 further increase in gas pressure causes the initiating multilayer coverage. Smaller pores in the sample are filled first. BET equation is used to calculate the surface area (Dollimore et al. 1976). During stage 4, further increase in gas pressure causes complete coverage of the sample and filling all of the pores (Hosseini et al. 2018).

\section{Results and discussion}

\section{Characterization of core samples}

The eight core plugs were used in this study, one carbonate sample from Ahwaz field (Iran), four carbonate samples of Bangestan group (Sarvak formation) and three carbonate samples of Asmari formation. Ahwaz carbonate sample was labeled with code $A_{1}$, Bangestan carbonate samples were denoted by $\mathrm{B}_{1}, \mathrm{~B}_{2}, \mathrm{~B}_{3}$ and $\mathrm{B}_{4}$, and other carbonate samples were named $K_{1}, K_{3}$ and $K_{4}$. Figure 6 shows some carbonate core samples used in this study.

First, dimensions of each plug were measured by caliper, and then their dry weight was measured by digital balance. Properties such as bulk volume, pore volume, grain density and porosity were measured by porosimeter and gas permeameter.

The measured properties and other information are shown in Table 1.

The porosimeter data are summarized in Table 2.

\section{Sampling}

The plugs were cut and converted to chips with the same thickness. Every plug was cut in same size from top to bottom surface. This enhances the accuracy of measurement via increasing the number of samples and creates much surface to scan and examine. Chips of carbonate plug samples are illustrated in Fig. 7. The chips which were chosen for the BET test are shown in Fig. 8.

\section{Determining specific surface area of chips samples by core scan}

A threshold was to define a range of colors or gray values that contains the particles or features to be measured. The gray is defined by two values. In Table 3, upper and lower threshold values, specific surface area of top and bottom surfaces, arithmetic average of specific surface area of each chips $\left(\overline{S_{\mathrm{sc}}}\right)$ and average specific surface area of plug sample $\left(\overline{S_{\mathrm{sp}}}\right)$ are given for K3 sample. 
Table 8 Specific surface area of selected chips by core scan and BET and corrected specific surface area of selected chips

\begin{tabular}{|c|c|c|c|c|}
\hline Sample & Selected chips & $\begin{array}{l}\text { Specific surface area of selected } \\
\text { chips by core scan }(1 / \mathrm{cm})\end{array}$ & $\begin{array}{l}\text { Specific surface area of selected } \\
\text { chips by BET }(1 / \mathrm{cm})\end{array}$ & $\begin{array}{l}\text { Corrected specific surface } \\
\text { area of selected chips (1/ } \\
\mathrm{cm})\end{array}$ \\
\hline \multirow[t]{4}{*}{ K1 } & 2 & $56,262.92$ & $32,212.6$ & $36,372.95$ \\
\hline & 4 & $56,632.79$ & $46,789.4$ & $40,351.74$ \\
\hline & 7 & $55,240.57$ & 47,348 & $39,915.32$ \\
\hline & 11 & $57,876.85$ & $40,618.2$ & $42,357.29$ \\
\hline \multirow[t]{3}{*}{ K3 } & 1 & $44,150.45$ & $53,248.68$ & $33,329.85$ \\
\hline & 6 & $41,813.92$ & 51,336 & $31,486.24$ \\
\hline & 8 & $43,898.6$ & 61,272 & $37,846.87$ \\
\hline \multirow[t]{2}{*}{ K4 } & 2 & $16,787.74$ & $29,790.6$ & $18,654.30$ \\
\hline & 5 & $36,576.99$ & $39,433.8$ & $30,985.04$ \\
\hline \multirow[t]{3}{*}{ A1 } & 4 & $19,851.26$ & 10,842 & $12,218.93$ \\
\hline & 6 & $15,221.5$ & $11,342.4$ & $11,152.47$ \\
\hline & 7 & $16,354.19$ & 12,093 & $11,857.48$ \\
\hline \multirow[t]{4}{*}{ B1 } & 1 & $22,813.46$ & $24,698.20$ & 22,900 \\
\hline & 4 & $23,212.97$ & $26,195.76$ & $24,085.73$ \\
\hline & 9 & $26,270.11$ & $26,171.83$ & $26,475.59$ \\
\hline & 11 & $26,235.51$ & $27,403.04$ & $26,687.48$ \\
\hline \multirow[t]{3}{*}{ B2 } & 2 & $28,143.58$ & $24,997.98$ & $29,564.75$ \\
\hline & 6 & $31,201.09$ & $32,476.22$ & $27,653.78$ \\
\hline & 10 & $32,105.18$ & $54,728.38$ & $30,859.78$ \\
\hline \multirow[t]{5}{*}{ B3 } & 3 & $41,307.79$ & $37,009.84$ & $15,130.26$ \\
\hline & 5 & $39,011.46$ & $41,351.10$ & $30,481.58$ \\
\hline & 8 & $38,740.11$ & $50,780.01$ & $13,947.24$ \\
\hline & 11 & $41,483.12$ & $65,537.29$ & $37,539.25$ \\
\hline & 13 & $41,837.69$ & $86,373.33$ & $40,717.27$ \\
\hline \multirow[t]{2}{*}{ B4 } & 4 & $45,317.17$ & $65,908.76$ & $40,727.69$ \\
\hline & 6 & $43,721.64$ & $80,759.19$ & $47,200.46$ \\
\hline
\end{tabular}

Table 9 Correlation coefficient, $\boldsymbol{R}^{\mathbf{2}}$, maximum error, mean squared error and mean absolute error of calibration curve

\begin{tabular}{ll}
\hline Correlation coefficient & 0.9599 \\
$R^{2}$ & 0.9197 \\
Maximum error & 0.3009 \\
Mean squared error & 0.0058 \\
Mean absolute error & 0.0381 \\
\hline
\end{tabular}

Arithmetic average of specific surface area $\left(\overline{S_{\text {sc }}}\right)$ is calculated for top and bottom surface areas of that chip. This is repeated for all 10 chips. Average specific surface area of each plug $\left(\overline{S_{\mathrm{sp}}}\right)$ is the arithmetic average of $\overline{S_{\mathrm{sc}}}$. The chips are selected which have $\overline{S_{\mathrm{sc}}}$ close to $\overline{S_{\mathrm{sp}}}$. According to Table 3, chips 1, 6 and 8 were selected for the BET test.

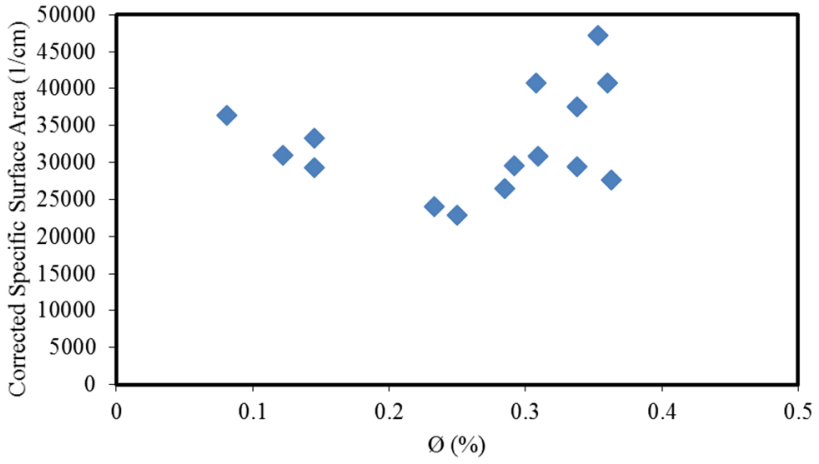

Fig. 10 Corrected specific surface area by calibration curve versus porosity 
Table 10 Corrected specific surface area and porosity of selected chips

\begin{tabular}{|c|c|c|c|}
\hline Sample & Selected chips & $\begin{array}{l}\text { Corrected specific surface } \\
\text { area of selected chips } \\
\left(S_{S_{\text {Correct }}}\right)(1 / \mathrm{cm})\end{array}$ & $\begin{array}{l}\text { Porosity of } \\
\text { selected chips } \\
(\%)\end{array}$ \\
\hline \multirow[t]{4}{*}{ K1 } & 2 & $36,372.95$ & 8.16 \\
\hline & 4 & $40,351.74$ & 7.7 \\
\hline & 7 & $39,915.32$ & 7.2 \\
\hline & 11 & $42,357.29$ & 8.76 \\
\hline \multirow[t]{3}{*}{$\mathrm{K} 3$} & 1 & $33,329.85$ & 12.98 \\
\hline & 6 & $31,486.24$ & 13.21 \\
\hline & 8 & $37,846.87$ & 16.34 \\
\hline \multirow[t]{2}{*}{$\mathrm{K} 4$} & 2 & $18,654.30$ & 12.06 \\
\hline & 5 & $30,985.04$ & 12.33 \\
\hline \multirow[t]{3}{*}{ A1 } & 4 & $12,218.93$ & 14.44 \\
\hline & 6 & $11,152.47$ & 13.83 \\
\hline & 7 & $11,857.48$ & 14.09 \\
\hline \multirow[t]{4}{*}{ B1 } & 1 & 22,900 & 25 \\
\hline & 4 & $24,085.73$ & 23.3 \\
\hline & 9 & $26,475.59$ & 28.5 \\
\hline & 11 & $26,687.48$ & 28.5 \\
\hline \multirow[t]{3}{*}{ B2 } & 2 & $29,564.75$ & 29.2 \\
\hline & 6 & $27,653.78$ & 36.3 \\
\hline & 10 & $30,859.78$ & 30.9 \\
\hline \multirow[t]{5}{*}{ B3 } & 3 & $15,130.26$ & 43.2 \\
\hline & 5 & $30,481.58$ & 32.9 \\
\hline & 8 & $13,947.24$ & 28.6 \\
\hline & 11 & $37,539.25$ & 33.8 \\
\hline & 13 & $40,717.27$ & 30.8 \\
\hline \multirow[t]{2}{*}{ B4 } & 4 & $40,727.69$ & 36 \\
\hline & 6 & $47,200.46$ & 35.3 \\
\hline
\end{tabular}

Table 11 Correlation coefficient, $R^{2}$, maximum error, mean squared error and mean absolute error of relationship

\begin{tabular}{ll}
\hline Correlation coefficient & 0.9538 \\
$R^{2}$ & 0.8937 \\
Maximum error & 0.2354 \\
Mean squared error & 0.0095 \\
Mean absolute error & 0.0602 \\
\hline
\end{tabular}

\section{Determination of porosity and permeability of selected samples}

The procedure of porosity and permeability measurement was explained earlier. Tables 4 and 5 indicate porosity and permeability for selected chips, respectively.
Determining the average specific surface area of selected chips $\left(\overline{S_{s c}}\right)$ for all plugs by core scan $\mathrm{DMT}^{3}$

In this section, the average specific surface area of chips for all plugs was measured by core scan which is shown in Table 6.

\section{Determining the specific surface area of selected chips by $\mathrm{DMT}^{3}$ and BET}

The specific surface areas of selecting chips estimated by the BET test (Adsorption test) are reported in Table 7. It should be mentioned that the dimension of these parameters is $1 /$ $\mathrm{cm}$. According to the following relations, the unit of specific surface area obtained from core scan device and the BET test is converted from $\mathrm{m}^{2}$ to $1 / \mathrm{cm}$.

$S_{S_{\text {Core scan }}}=\frac{S_{S_{\text {Core scan }} \times 10^{4} \times \text { Number of chip }}}{(1-\varnothing) \times V_{\text {bulk }}}$ for core scan device

$S_{S_{\mathrm{BET}}=S_{S_{\mathrm{BET}}} \times 10^{4} \times \rho_{\mathrm{gr}}}$ for BET test

\section{Calibration curve}

It was decided to calibrate core scan device by BET measured data. By using this curve, BET test data can be generated for known values of core scan data accurately and minimum error. In order to do this, the some chips from each plug sample were selected and then specific surface area was measured by core scan. These chips were crushed and sieved by 80 mesh, and then the BET test was carried out, and specific surface area was measured by adsorption and desorption processes. First, specific surface area of BET and core scan methods was normalized between 0 and 1 by Eureqa software. Then, we plotted the chart of the normalized specific surface area obtained by BET method vs. the normalized specific surface area obtained by core scan method as a calibration curve as shown in Fig. 9. According to this figure, the experimental relationship was obtained by fitting data. Specific surface area of selected chips by core scan and BET methods and corrected specific surface area of selected chips obtained by calibration curve are indicated in Table 8.

The correlation coefficient, $R^{2}$, maximum error, mean squared error and mean absolute error of calibration relationship are reported in Table 9.

The relationship is: 
Fig. 11 Corrected specific surface area by calibration curve versus iteration number of estimation
Table 12 Normalized corrected specific surface area, porosity and permeability of selected chips

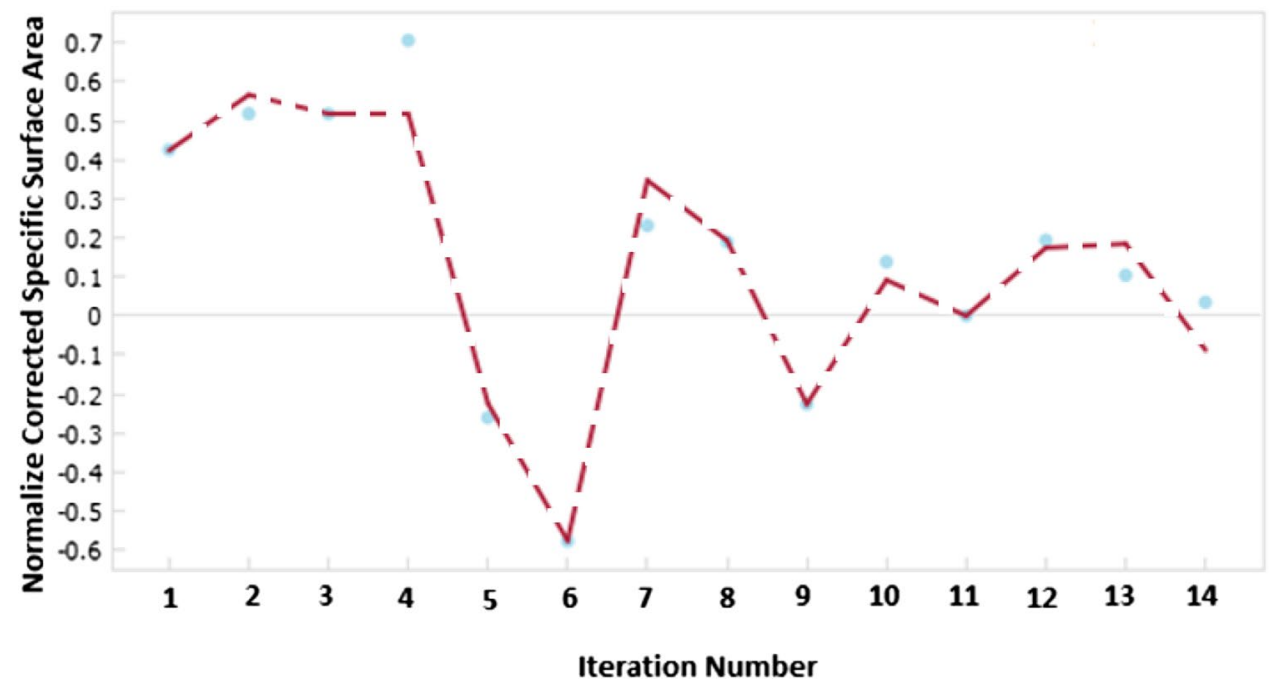

\begin{tabular}{|c|c|c|c|c|}
\hline Sample & Selected chips & $\begin{array}{l}\text { Normalized corrected } \\
\text { specific surface area }\end{array}$ & $\begin{array}{l}\text { Porosity of selected } \\
\text { chips }(\%)\end{array}$ & $\begin{array}{l}\text { Normalized perme- } \\
\text { ability of selected } \\
\text { chips }\end{array}$ \\
\hline \multirow[t]{4}{*}{ K1 } & 2 & 0.3912 & 8.16 & 1 \\
\hline & 4 & 0.4171 & 7.7 & 0.1957 \\
\hline & 7 & 0.3807 & 7.2 & 0.1926 \\
\hline & 11 & 0.3697 & 8.76 & 0.1786 \\
\hline \multirow[t]{3}{*}{ K3 } & 1 & 0.3028 & 12.98 & 0.3061 \\
\hline & 6 & 0.2911 & 13.21 & 0.2854 \\
\hline & 8 & 0.3241 & 16.34 & 0.2457 \\
\hline \multirow[t]{2}{*}{ K4 } & 2 & 0.1681 & 12.06 & 0.2459 \\
\hline & 5 & 0.2348 & 12.33 & 0.4367 \\
\hline \multirow[t]{3}{*}{ A1 } & 4 & 0.1850 & 14.44 & 0.1380 \\
\hline & 6 & 0.1769 & 13.83 & 0.1314 \\
\hline & 7 & 0.1801 & 14.09 & 0.1343 \\
\hline \multirow[t]{4}{*}{ B1 } & 1 & 0 & 25 & 0.1551 \\
\hline & 4 & 0.0344 & 23.3 & 0.0652 \\
\hline & 9 & 0.1038 & 28.5 & 0.0262 \\
\hline & 11 & 0.1091 & 28.5 & 0.0262 \\
\hline \multirow[t]{3}{*}{ B2 } & 2 & 0.1935 & 29.2 & 0.0081 \\
\hline & 6 & 0.1380 & 36.3 & 0.0048 \\
\hline & 10 & 0.2311 & 30.9 & 0.0364 \\
\hline \multirow[t]{5}{*}{ B3 } & 3 & -0.2256 & 43.2 & 0.3350 \\
\hline & 5 & -0.5765 & 32.9 & 0.0012 \\
\hline & 8 & -0.2599 & 28.6 & 0.0023 \\
\hline & 11 & 0.4251 & 33.8 & 0.0084 \\
\hline & 13 & 0.5174 & 30.8 & 0.0023 \\
\hline \multirow[t]{2}{*}{ B4 } & 4 & 0.5177 & 36 & 0 \\
\hline & 6 & 0.7057 & 35.3 & 0.0023 \\
\hline
\end{tabular}


Table 13 Correlation coefficient, $R^{2}$, maximum error, mean squared error and mean absolute error of correlation

\begin{tabular}{ll}
\hline Correlation coefficient & 0.9751 \\
$R^{2}$ & 0.9504 \\
Maximum error & 0.1880 \\
Mean squared error & 0.0054 \\
Mean absolute error & 0.0473 \\
\hline
\end{tabular}

Table 14 Orenburg field carbonated samples properties (Evbuomwan 2009)

\begin{tabular}{lllll}
\hline Sample & Porosity $(\%)$ & $\begin{array}{l}\text { Perme- } \\
\text { ability } \\
(\mathrm{mD})\end{array}$ & $\begin{array}{l}\text { Specific } \\
\text { surface area } \\
\left(\mathrm{m}^{2}\right)\end{array}$ & $\begin{array}{l}\text { Normalized } \\
\text { specific surface } \\
\text { area }\end{array}$ \\
\hline 1 & 10.3 & 0.52 & 10,164 & 1 \\
2 & 11 & 1.93 & 5810 & 0.5439 \\
3 & 12.4 & 1.89 & 7000 & 0.6686 \\
4 & 13.2 & 3.65 & 5551 & 0.5168 \\
5 & 13.5 & 3.4 & 2866 & 0.2356 \\
6 & 14.5 & 5.34 & 2285 & 0.1748 \\
7 & 15.7 & 16 & 3451 & 0.2969 \\
8 & 17 & 39 & 2261 & 0.1722 \\
9 & 18.2 & 181 & 1274 & 0.0689 \\
10 & 20 & 258 & 1050 & 0.0454 \\
\hline
\end{tabular}

$$
\begin{aligned}
S_{S_{\mathrm{BET}}}= & A \cdot S_{S_{\text {Core scan }}}^{\operatorname{Sin}\left(\operatorname{Sin}\left(\exp \left(B . S_{s_{\text {Core scan }}^{2}}\right)\right)\right.}-C \cdot S_{S_{\text {Core scan }}} \\
& \cdot \exp \left(\left(D \cdot S_{S_{\text {Core scan }}}\right)^{\operatorname{Sin}\left(\exp \left(E \cdot S_{s_{\text {Core scan }}}\right)\right)}\right)
\end{aligned}
$$

where $S_{S_{\mathrm{BET}}}$ is the specific surface area of selected chips by the BET test $(1 / \mathrm{cm}), S_{s_{\text {Core scan }}}$ is the specific surface area of selected chips by core scan device, $A=0.8686, B=3.2460$, $C=0.1721, D=0.8176$ and $E=11.3207$.
Thus, by using this calibration correlation, corrected specific surface area $\left(S_{S_{\text {Correct }}}\right)$ is generated. This parameter was obtained from specific surface area of core scan by correcting BET surface data and was used in the experimental relationship in this study to correlate with porosity and permeability. This parameter was applied because of the low accuracy of core scan device in measuring specific surface area and the fact that the BET test was not economically efficient.

\section{Correlation between corrected specific surface area and porosity}

The assumptions for determination of a relationship are:

1. Specific surface area is a function of porosity, permeability, tortuosity $(\tau)$, formation resistivity factor $(F)$ and irreducible water saturation $\left(S_{\text {wir }}\right)$.

2. $S_{\text {wir }}$ is considered to be constant for studied plugs.

3. Tortuosity, irreducible water saturation and formation resistivity factor are not included in relationships.

In this study, the corrected specific surface area was used because this parameter is more accurate than specific surface area, obtained by calibration correlation.

The relationship between porosity and corrected specific surface area for carbonated chips samples is presented in Fig. 10. According to this figure, the corrected specific surface area $\left(S_{S_{\text {Corret }}}\right)$ which is obtained by calibration curve was plotted versus the porosity of selected chips and the relationship was obtained by fitting data. It was observed in low porosity values, corrected specific surface area has a
Fig. 12 Specific surface area of Orenburg data versus experimental relationship in this study

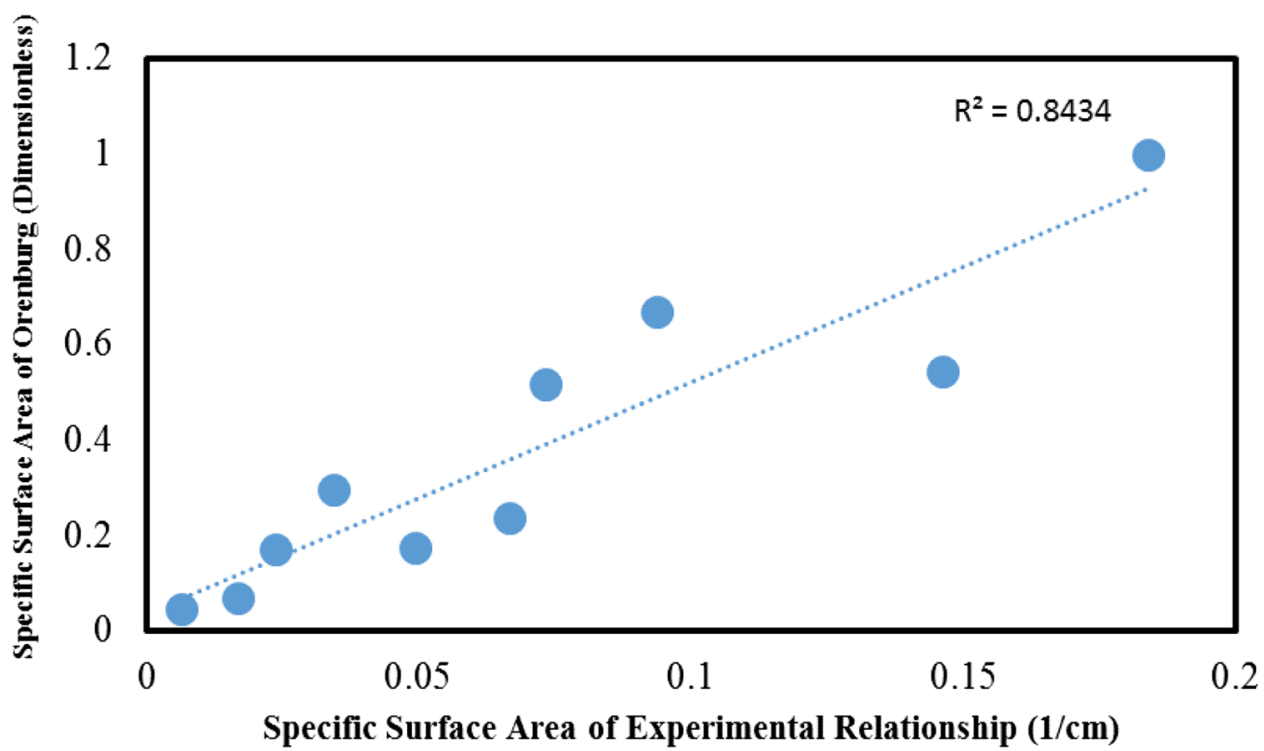

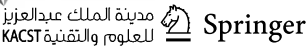



Orenburg data versus Kotyakhov model

Fig. 14 Specific surface area values of Orenburg data versus Pirson model
Fig. 13 Specific surface area of
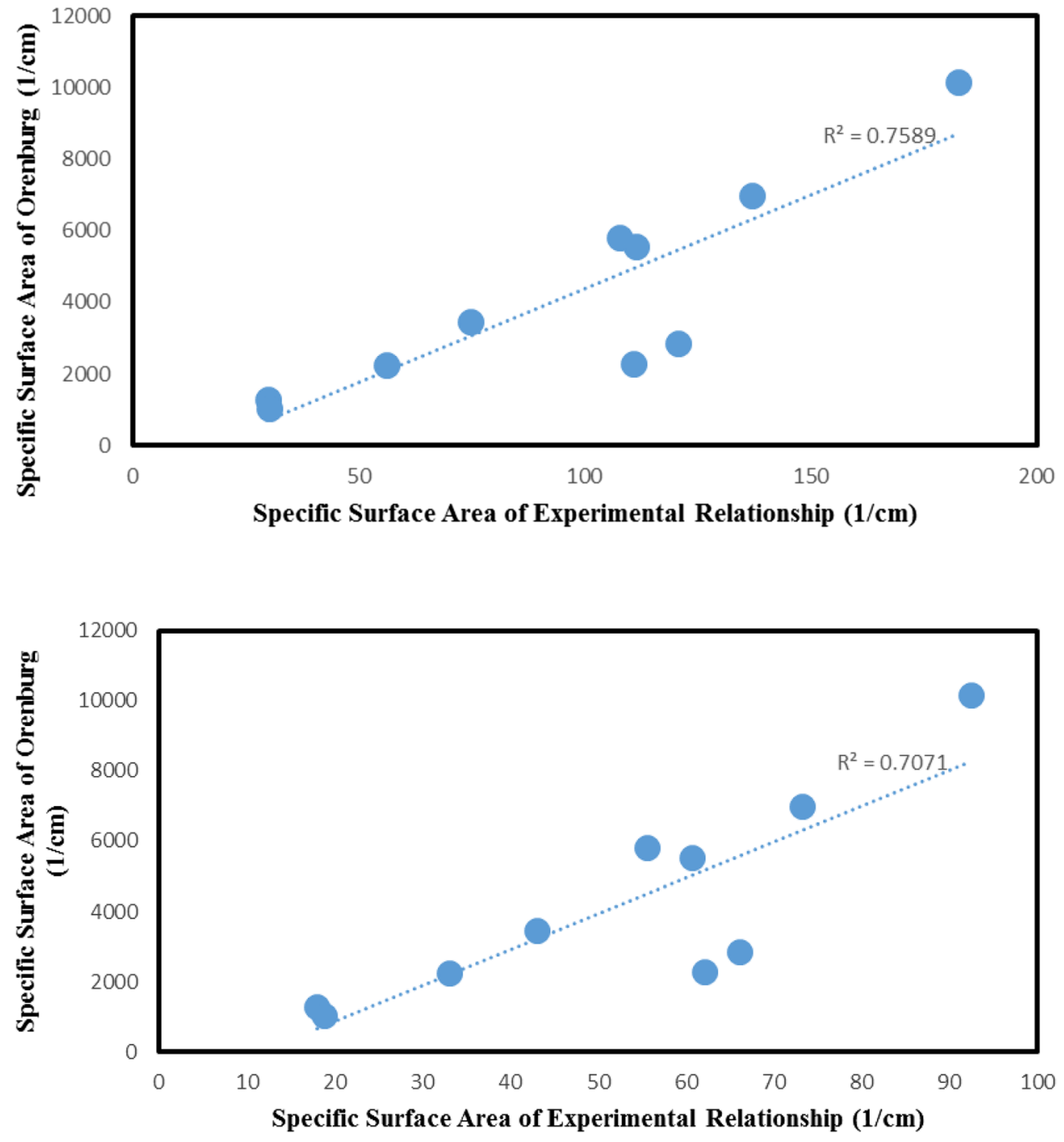

Fig. 15 Summary of comparison of correlations and different models (Kotyakhov 1949; Pirson 1958)

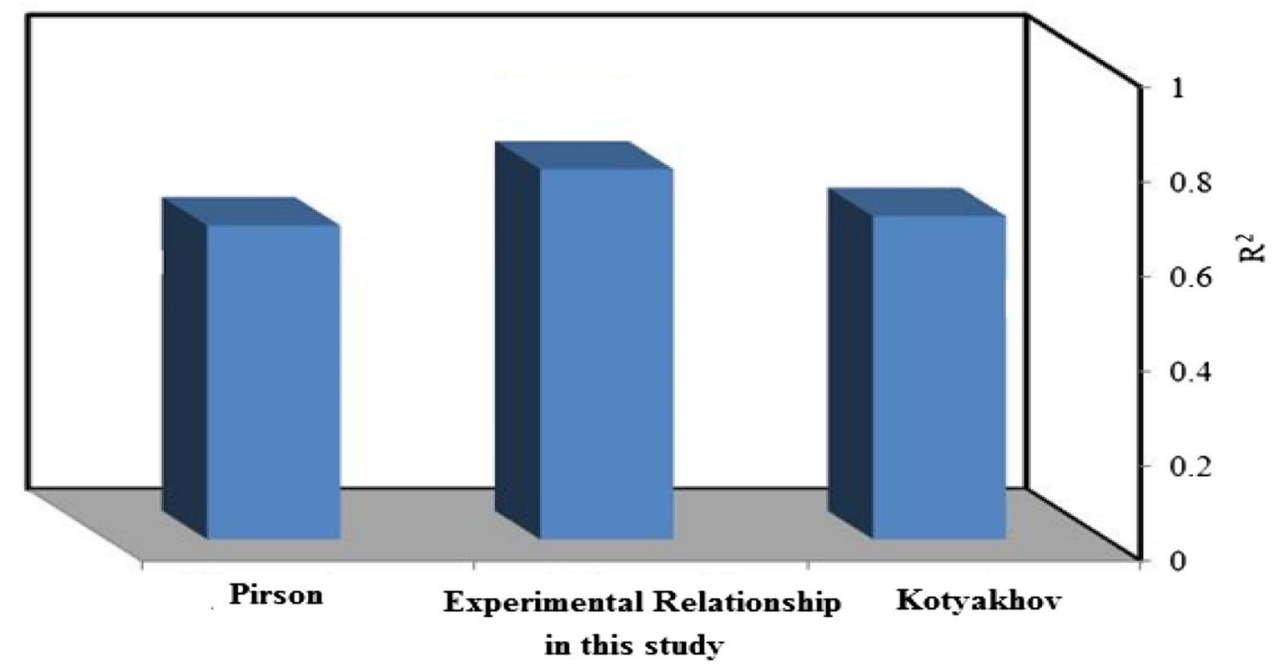

decreasing trend and then starts to increase at higher porosity values. This trend indicates that increasing trend specific surface area versus porosity occurs at higher porosity values. The corrected specific surface area data and porosity of selected chips are shown in Table 10. The correlation coefficient, $R^{2}$, maximum error, mean squared error 
and mean absolute error of relationship between porosity and corrected specific surface area are demonstrated in Table 11.

The relationship is:

$$
\begin{aligned}
S_{S_{\text {Correct }}=} & A+B \cdot \operatorname{Sin}(C \cdot \phi)+\phi \cdot \operatorname{Sin}\left(D \cdot \phi^{2}\right) \\
& +\phi \cdot \operatorname{Sin}\left(E \cdot \phi \cdot \operatorname{Sin}\left(F \cdot \phi^{2}\right)\right) \\
& -G \cdot \operatorname{Sin}(H \cdot \phi) \cdot \operatorname{Sin}\left(\operatorname{Sin}\left(I \cdot \phi^{2}\right)\right)
\end{aligned}
$$

where $\left(S_{S_{\text {Correct }}}\right)$ is the corrected specific surface area of selected chips $(1 / \mathrm{cm}), \emptyset$ is the porosity of selected chips (\%), $A=0.2001, B=0.2232, C=1658.0974, D=52.9306$, $E=78.2946, F=52.9306, G=0.2837, H=1658.0974$ and $I=52.9306$.

\section{Specific surface area relation with porosity and permeability}

First, corrected specific surface area, porosity and permeability were normalized. Then, normalized corrected specific surface area $\left(S_{S_{\text {Correct }}}\right)$ was obtained by calibration curve. Figure 11 shows the normalized corrected specific surface area against iteration number of estimation. Table 12 shows the normalized corrected values of specific surface area, normalized porosity and permeability of selected chips. Finally, the relationship was obtained by fitting normalized corrected specific surface area to porosity and permeability of selected chips. The correlation coefficient, $R^{2}$, maximum error, mean squared error and mean absolute error of this relationship are reported in Table 13.

The relationship is:

$$
S_{S_{\text {Correct }}}=\frac{A \cdot \phi+B \cdot \phi}{\left(C \cdot k_{n}+D \cdot \operatorname{Cos}\left(E \cdot \phi+F \cdot k_{n}^{4}\right)\right)}-G-\left(H \cdot k_{n}\right)
$$

where $\emptyset$ is the porosity of selected chips (\%), $k_{\mathrm{n}}$ is the normalized permeability of selected chips, and $\left(S_{S n_{\text {Correct }}}\right)$ is the normalized corrected specific surface area of selected chips (dimensionless), $A=3.6513, B=1.1391, C=3.8860$, $D=6.1718, E=15.9758, F=5444.4802, G=0.8527$ and $H=0.3025$.

\section{Validation of measured data with other models based on field data}

The specific surface area estimated from the relationship in this study and some other models was compared with data from carbonate samples of the Orenburg field in Russia. Table 14 shows the porosity, permeability and specific surface area and normalized specific surface area of this field (Evbuomwan 2009). The results are demonstrated in Figs. 12, 13 and 14. The specific surface area was plotted against the estimated specific surface area in this study and other models. It is observed that the relationship in this study has the highest accuracy $\left(R^{2}=0.84\right)$ among other predictive models.

The summary of accuracy of various correlation sand different models for Orenberg field is presented in Fig. 15.

\section{Conclusion}

1. The results from experimental data measured by core scan $\mathrm{DMT}^{3}$ device and the BET test indicate that as porosity increases from 0 to 0.2 , the specific surface area decreases and reaches a minimum and again the trend becomes increasing. A new relationship between porosity and specific surface area was developed $\left(R^{2}=0.89\right)$.

2. A calibration curve was developed based on core scan $\mathrm{DMT}^{3}$ and BET tests with $R^{2}=0.92$. According to this curve, the data obtained by the BET test can be estimated from core-scan-measured surface area data.

3. A new relationship was developed between specific surface area, porosity and permeability $\left(R^{2}=0.95\right)$. This correlation eliminates the need for direct measurement of specific surface area with advanced testing methods such as the BET test. This experimental correlation has acceptable accuracy with $R^{2}=0.84$.

Open Access This article is licensed under a Creative Commons Attribution 4.0 International License, which permits use, sharing, adaptation, distribution and reproduction in any medium or format, as long as you give appropriate credit to the original author(s) and the source, provide a link to the Creative Commons licence, and indicate if changes were made. The images or other third party material in this article are included in the article's Creative Commons licence, unless indicated otherwise in a credit line to the material. If material is not included in the article's Creative Commons licence and your intended use is not permitted by statutory regulation or exceeds the permitted use, you will need to obtain permission directly from the copyright holder. To view a copy of this licence, visit http://creativecommons.org/licenses/by/4.0/.

\section{References}

Basbug B, Karpyn ZT (2007) Estimation of permeability from porosity, specific surface area, and irreducible water saturation using an artificial neural network. In: Latin American and Caribbean petroleum engineering conference, Buenos Aires, Argentina, 11, 15-18. https://doi.org/10.2118/107909-MS

Brooks C, Purcell W (1952) Surface area measurements on sedimentary rocks. Society of petroleum engineers journal fall meeting of the petroleum branch of AIME, Texas

Buryakovsky L, Chilingar GV, Rieke HH, Shin S (2012) Fundamentals of the petrophysics of oil and gas reservoirs. Wiley, Hoboken

Chilingarian GV, Chang J, Bagrintseva KI (1990) Empirical expression of permeability in terms of porosity, specific surface area,

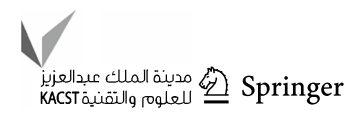


and residual water saturation of carbonate rocks. J Pet Sci Eng 4(4):317-322

Dollimore D, Spooner P, Turner A (1976) The bet method of analysis of gas adsorption data and its relevance to the calculation of surface areas. Surf Technol 4:121-160. https://doi.org/10.1016/03764583(76)90024-8

Donaldson EC, Kendall RF, Baker BA, Manning FS (1975) Surface area measurement of geologic materials. Soc Pet Eng J 15:111116. https://doi.org/10.2118/4987-PA

Evbuomwan I (2009) The structural characterisation of porous media for use as model reservoir rocks, adsorbents and catalysts. Ph.D., University of Bath, UK

Fatt J, Kumar J (1970) Nuclear magnetic resonance study of porosity, permeability and surface area of unconsolidated porous materials. Log Anal 11(01)

Hosseini E, Hajivand F, Yaghodous A (2018) Experimental investigation of EOR using low-salinity water and nanoparticles in one of southern oil fields in Iran. Energy Sources Part A Recovery Util Environ Effects 40:1974-1982. https://doi.org/10.1080/15567 036.2018 .1486923

Kotyakhov FI (1949) Relationship between major physical parameters of sandstones. Oil Econ 12:29-32

Lee BH, Lee SK (2013) Effects of specific surface area and porosity on cube counting fractal dimension, lacunarity, configurational entropy, and permeability of model porous networks: random packing simulations and NMR micro-imaging study. J Hydrol 496:122-141. https ://doi.org/10.1016/j.jhydrol.2013.05.014
Li D, Engler TW (2001) Development of a new equation and an algorithm to estimate permeabilities for clean formations from resistivity logs. Soc Pet Eng J 14:1-9

Mortensen J, Engstrom F, Lind I (2013) The relation among porosity, permeability, and specific surface of chalk from the gorm field, danish north sea. SPE Reservoir Eval Eng 1(03):245-251

Pirson SJ (1958) Oil reservoir engineering. McGraw-Hill Book Co., New York

Sheng J (2010) Modern chemical enhanced oil recovery: theory and practice, 1st edn. Gulf Professional Publishing, Houston

Tiab D, Donaldson EC (2011) Petrophysics: theory and practice of measuring reservoir rock and fluid transport properties. Gulf Professional Publishing, Houston

Torsaeter O, Abtahi M (2003) Experimental reservoir engineering laboratory work book for petroleum engineering. Department of Petroleum Engineering, Norway

Wyllie MRJ, Rose WD (1950) Application of the kozeny equation to consolidated porous media. Nature 165(4207):972-972

Zafari MJ (2014) Experimental investigation of relationship between pore size distribution and wettability alteration of reservoir rocks. M.Sc. Petroleum University of Technology, Iran

Publisher's Note Springer Nature remains neutral with regard to jurisdictional claims in published maps and institutional affiliations. 